(C) 1980. The Genetical Society of Great Britain

\title{
ESTIMATE OF VARIANCE EFFECTIVE POPULATION SIZE IN A LABORATORY CERATITIS POPULATION
}

\author{
DOMITIEN DEBOUZIE \\ Laboratoire de Biométrie, Université Claude Bernard, 43, bd du 11 novembre 69622 \\ Villeurbanne Cedex (France)
}

Received 1.ii.80

IT is not easy to define effective population size because this theoretical parameter depends on several factors: the number of males and females of reproductive age, the distribution of their family sizes, the intra-population inbreeding coefficient and the temporal changes in population size (Wright, 1931, 1969; Kimura and Crow, 1963). Because of theoretical (Lewontin, 1974) and practical difficulties (definition of spatial population limits, choice of sampling designs), very few estimates are available (see Crow and Morton, 1955; Greenwood, 1974 and Begon, 1977 for examples in invertebrates). In this note, we propose a laboratory approach based on experimental simulations of the ecological microsystem constituted by an insect species and a fruit with its microorganisms. The system may be viewed as a model for discrete and temporary patches of habitat. Fine analysis of the physiological heterogeneity in offspring produced by each microsystem allows an estimation of the distribution of family sizes and thus of the variance effective size for the group of adults.

Twenty pairs of Mediterranean fruit-fly adults $P_{0}$ (Ceratitis capitata) were allowed to lay eggs in a banana as long as it attracted them (about 7 days, Debouzie, 1980). All the adult offspring $F_{1}$ were removed from the cage each day and divided into isolated pairs according to their emergence order. Each pair was placed in a small cage (Debouzie, 1980) which contained artificial food and a plastic needle-pierced cupel for egg-laying (Feron et al., 1958). Numbers of $F_{2}$ eggs laid and of dead $F_{1}$ adults were counted daily until the death of the females. The eggs are placed on artificial medium (Feron et al., 1958), under uncrowded conditions; the number of adult $F_{2}$ offspring was counted for each $F_{1}$ pair. The isolated pair technique is painstaking with Ceratitis adults and we only performed two replicates; the conclusions for both agreed.

Results are summarized in the table. Like Begon (1977) and Gill (1978), we first calculate a corrected size $N^{\prime}$ which takes into account the difference between number of males and females, then the variance effective size $N_{e(v)}$ since the number of effective gametes per individual may be estimated as twice the number of $F_{2}$ adults produced by each $F_{1}$ pair. Our experimental results show that: $N^{\prime} \simeq N \delta^{\prime}+N q$, and $N_{e(v)} / N^{\prime}=0 \cdot 41$. This ratio is lower than those obtained by Crow and Morton (1955) on different strains of Drosophila melanogaster. In natural populations, $N_{e(v)} / N$ varies from 0.01 to 0.9 (Crow and Morton, 1955; Merrell, 1968; Greenwood, 1974; Begon, 1977; Gill, 1978; see also Wright, 1977). The index of variability in progeny number $\left(V_{k} / \bar{k}\right)$, proposed by Crow and Morton (1955), describes the heterogeneity between family sizes among the members of the population. The average values of the unadjusted $\left(V_{k} / \bar{k}=262, \bar{k}=133\right)$ or adjusted 
TABLE

Computation of the variance effective number for two Ceratitis laboratory populations

Replicate

Number of females $F_{1}: N q^{a}$

12

Number of males $\mathrm{F}_{1}: N{ }^{\star}$

6140

Corrected size $N^{\prime b}$

$81 \quad 42$

Average effective number of gametes produced by adult $\mathrm{F}_{1}(\bar{k})$

Index of variability in progeny number $\left(V_{k} / \bar{k}\right)$

Adjusted index $(\bar{k}=2)$

Adjusted variance effective size $N_{e(v)}{ }^{c}$

Ratio $N_{e(v)} / N^{\prime}$

${ }^{\text {a }}$ Only $N \uparrow$ pairs are formed, surplus males replace those dying in already existing pairs.

${ }^{\mathrm{b}} N^{\prime}=4 \cdot N \delta^{\prime} \cdot N q /\left(N q+N \delta^{\star}\right)$

${ }^{c} N_{e(v)}=\left(N^{\prime}-1\right) \cdot \bar{k} /\left(1+V_{k} / \bar{k}\right)$

$\left(V_{k} / \bar{k}=3 \cdot 87, \bar{k}=2\right)$ index are higher than those obtained by Crow and Morton (1955) on Drosophila melanogaster populations. Three factors can explain the large physiological heterogeneity:

1. One third of the females lay no eggs; competition for natural food during larval stages and the technique of isolated pairs may be implicated.

2. $F_{1}$ adult longevity and weight vary greatly,-between 4 and 30 days and between 3.0 and $6.3 \mathrm{mg}$ for fresh emergence weight, respectively, and are correlated with fecundity (Debouzie, 1980).

3. Fecundity seems highly variable in Ceratitis (Debouzie, 1980; Chaillou, 1969). The technique of isolated pairs probably reduces productivity and increases its variance; however, its effect on variance effective size can hardly be estimated because no Ceratitis marked strain has been described.

The ecological microsystem used (Ceratitis-banana) provides a very simplified picture of the offspring that could be actually produced by each fruit. In the field, migration and demographic cycles in Mediterranean fruit-fly populations would greatly affect effective population number. Fine analysis of the structure and dynamics of these populations are required. In conclusion, our experimental simulation shows that, in laboratory Ceratitis populations reared from a single banana, the index of variability in progeny number is much higher than those obtained in classical laboratory conditions.

Acknowledgments.-The author is grateful to R. Grantham, R. Allemand, M. Bouletreau, C. Biemont, J. M. Legay and an anonymous referee for their helpful comments on the manuscript. Thanks are due to A. Heizmann and D. Longchambon for their valuable technical assistance. The laboratory is associated with C.N.R.S. (No. 243).

\section{REFERENCES}

BEGON, M. 1977. The effective size of a natural Drosophila subobscura population. Heredity, 38, 13-18.

CHAILlOU, C. 1969. Etude de l'influence de la présence du pondoir sur la fécondité de Ceratitis capitata Wied. (Diptère, Trypetidae). Thèse Doct. 3ème cycle, Paris.

CROW, J. F., AND MORTON, N. E. 1955. Measurement of gene frequency drift in small populations. Evolution, 9, 202-214. 
DEBOUZIE, D. 1980. Analyse au laboratoire d'un microécosystème isolé. Etude d'un fruit colonisé par la mouche méditerranéenne des fruits, Ceratitis capitata Wied. Thèse Doct. Etat, Lyon.

FERON, M., DELANOUe, P., AND SORIA, F. 1958. L'élevage massif artificiel de Ceratitis capitata Wied. Entomophaga, 3, 45-53.

GILL, D. E. 1978. Effective population size and interdemic migration rates in a metapopulation of the red-spotted newt, Notophthalmus viridescens (Rafinesque). Evolution, 32, 839-849.

GREENWOOD, J. J. D. 1974. Effective population numbers in the snail Cepaea nemoralis. Evolution, 28, 513-526.

KIMURA, M., AND CROW, J. F. 1963. The measurement of effective population number. Evolution, 17, 279-288.

LEWONTIN, R. C. 1974. The genetic basis of evolutionary change. Columbia University Press, New York.

MERRELL, D. J. 1968. A comparison of the estimated size and the "effective size" of breeding populations of the leopard frog, Rana pipiens. Evolution, 22, 274-283.

WRIGHT, S. 1931. Evolution in Mendelian populations. Genetics, 16, 97-159.

WRIGHT, S. 1969. Evolution and the Genetics of Populations. Volume II. The Theory of Gene Frequencies. University of Chicago Press, Chicago.

WRIGHT, S. 1977. Evolution and the Genetics of Populations. Volume III. Experimental results and evolutionary deduction. University of Chicago Press, Chicago. 